\title{
New Onset Diabetes Mellitus in Living Donor versus Deceased Donor Liver Transplant Recipients: Analysis of the UNOS/OPTN Database
}

\author{
Anitha D. Yadav, ${ }^{1}$ Yu-Hui Chang, ${ }^{2}$ Bashar A. Aqel, ${ }^{1}$ Thomas J. Byrne, ${ }^{1}$ \\ Harini A. Chakkera, ${ }^{3}$ David D. Douglas, ${ }^{1}$ David C. Mulligan, ${ }^{4}$ Jorge Rakela, ${ }^{1}$ \\ Hugo E. Vargas, ${ }^{1}$ and Elizabeth J. Carey ${ }^{1}$ \\ ${ }^{1}$ Division of Hepatology, Mayo Clinic Hospital, 5777 E. Mayo Boulevard, Phoenix, AZ 85054, USA \\ ${ }^{2}$ Division of Health Sciences Research, Mayo Clinic Hospital, 5777 E. Mayo Boulevard, Phoenix, AZ 85054, USA \\ ${ }^{3}$ Division of Nephrology, Mayo Clinic Hospital, 5777 E. Mayo Boulevard, Phoenix, AZ 85054, USA \\ ${ }^{4}$ Division of Transplant Surgery, Mayo Clinic Hospital, 5777 E. Mayo Boulevard, Phoenix, AZ 85054, USA
}

Correspondence should be addressed to Elizabeth J. Carey; carey.elizabeth@mayo.edu

Received 30 June 2013; Accepted 22 August 2013

Academic Editor: Parmjeet Randhawa

Copyright (C) 2013 Anitha D. Yadav et al. This is an open access article distributed under the Creative Commons Attribution License, which permits unrestricted use, distribution, and reproduction in any medium, provided the original work is properly cited.

\begin{abstract}
New onset diabetes after transplantation (NODAT) occurs less frequently in living donor liver transplant (LDLT) recipients than in deceased donor liver transplant (DDLT) recipients. The aim of this study was to compare the incidence and predictive factors for NODAT in LDLT versus DDLT recipients. The Organ Procurement and Transplant Network/United Network for Organ Sharing database was reviewed from 2004 to 2010, and 902 LDLT and 19,582 DDLT nondiabetic recipients were included. The overall incidence of NODAT was $12.2 \%$ at 1 year after liver transplantation. At 1, 3, and 5 years after transplant, the incidence of NODAT in LDLT recipients was 7.4, 2.1, and 2.6\%, respectively, compared to $12.5,3.4$, and $1.9 \%$, respectively, in DDLT recipients. LDLT recipients have a lower risk of NODAT compared to DDLT recipients (hazard ratio $=0.63(0.52-0.75), P<0.001)$. Predictors for NODAT in LDLT recipients were hepatitis C (HCV) and treated acute cellular rejection (ACR). Risk factors in DDLT recipients were recipient male gender, recipient age, body mass index, donor age, donor diabetes, HCV, and treated ACR. LDLT recipients have a lower incidence and fewer risk factors for NODAT compared to DDLT recipients. Early identification of risk factors will assist timely clinical interventions to prevent NODAT complications.
\end{abstract}

\section{Introduction}

New onset diabetes mellitus after transplantation (NODAT) is a serious metabolic complication with a reported incidence of $10 \%$ to $36 \%$ in liver transplant recipients [1-8]. The variation in the incidence of NODAT is due to differences in the diagnostic criteria for NODAT, patient characteristics,duration of the study period, and variation of immunosuppressive regimens used. Studies suggest that NODAT in liver transplant recipients is associated with a significant increase in cardiovascular disease, infection, and decreased graft survival [6-10]. Multiple risk factors are known to be associated with NODAT $[1-6,11,12]$. Age, male gender, body mass index (BMI), hepatitis C virus infection (HCV), impaired fasting glucose, immunosuppressive medications, and acute cellular rejection (ACR) episodes are documented as predictive factors for NODAT. The existing literature focuses on the prevalence and risk factors for NODAT in deceased donor liver transplant (DDLT) recipients [16]. However, the incidence and predictors of NODAT in living donor liver transplant (LDLT) recipients are not well established. In a single center retrospective study of 84 Chinese LDLT recipients, the incidence of NODAT was 14.9\% [13]. The only risk factor identified was body mass index.

Previous studies demonstrated a lower risk of NODAT in LDLT recipients $[1,2]$. Suggested contributory factors for 
this decreased risk include favorable recipient and donor characteristics (younger donor age and lower MELD score and BMI among recipients). There are no confirmatory studies evaluating the lower incidence and predictive factors of NODAT in LDLT recipients. Hence, this study aimed to identify and compare the incidence and risk factors for NODAT in LDLT versus DDLT recipients using a large national database. The incidence of NODAT over a five-year follow-up after liver transplantation was also assessed.

\section{Methods}

The Organ Procurement and Transplant Network/United Network for Organ Sharing (OPTN/UNOS) database from 2004 to 2010 was analyzed. A total of 20,484 recipients with pretransplant diabetes, multiorgan transplant, and retransplantation were excluded. The study group included 902 LDLT and 19,582 DDLT recipients, none of whom had diabetes mellitus prior to liver transplantation. All patients had at least one follow-up recorded in the database. The incidence of NODAT at 6 months and consecutive 5 years after-transplant in both LDLT and DDLT groups was evaluated.

Recipient risk factors included age at transplant, gender, race (African-American (AA), Caucasian, and Hispanic), BMI, etiology of liver disease (alcoholic liver disease (ALD), $\mathrm{HCV}$, nonalcoholic steatohepatitis (NASH), and others), history of diabetes, and model for end-stage liver disease (MELD) score at the time of transplant. Donor risk factors included age, gender, race, and history of diabetes. Transplant related variables included cold ischemia time, treated ACR episodes, steroid induction, and use of calcineurin inhibitor.

\section{Definition of NODAT}

NODAT was identified in recipients who had at least one record of diabetes during the posttransplant follow-up period. The UNOS Transplant Recipient Follow-up form does not define the precise diagnostic criteria for NODAT. The onset of diabetes is documented as "yes" or "no" on the UNOS follow-up record.

\section{Statistical Analysis}

Statistical analysis was performed using two-sample $t$-tests to compare continuous variables and chi-square tests to compare categorical variables. The Kaplan-Meier product limit method was used to estimate the survival rate, and logrank test was used to compare the overall survival between subgroups for each of the potential risk factors. Since the outcome of interest was time to the onset of NODAT after transplant, patients were considered censored in cases of death, graft loss, or loss to follow-up. The maximum followup duration was 5 years after transplant. To evaluate the risk factors for NODAT, Cox proportional hazard modeling was employed and the hazard ratios (HR) were reported. Univariate analysis was performed first, and variables with statistical significance were evaluated by multivariate analysis. All $P$ values were two sided, and a $P$ value of less than or equal

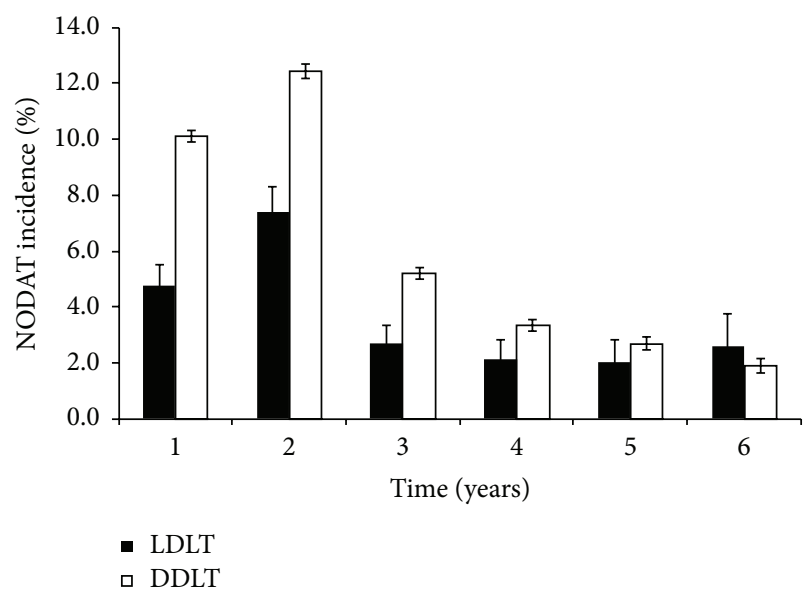

FIGURE 1: Incidence of NODAT in LDLT and DDLT recipients over time.

to 0.05 was considered statistically significant. All analysis was performed using SAS 9.1 (SAS institute, Cary, NC) and graphs were created using R 2.12.1 ( $\mathrm{R}$ foundation for statistical computing, Vienna, Austria).

\section{Results}

A total of 902 LDLT and 19,582 DDLT recipients were included in our study. The baseline demographic statistics for LDLT and DDLT recipients are shown in Table 1. The mean age in the LDLT cohort was $50.2 \pm 12.2$ and for DDLT was $52.7 \pm 10.2$ years $(P<0.001)$.

The overall incidence of NODAT was $12.2 \%$ at 1 year after transplantation. At 1, 3, and 5 years after transplant, the incidence of NODAT in LDLT was 7.4, 2.1, and 2.6\%, respectively, compared to $12.5,3.4$, and $1.9 \%$, respectively, in DDLT (Figure 1). The incidence of NODAT decreased as the duration of follow-up increased.

Kaplan-Meier plots for NODAT-free survival for donor type and HCV liver disease are shown in Figure 2. Higher NODAT-free survival was observed in LDLT compared to DDLT recipients $(87.7 \%, 83 \%$, and $68.3 \%$ versus $77.9 \%, 70.5 \%$, and $62 \%$ at 1,3 , and 5 years, resp., $(P<0.001))$.

Univariate analyses demonstrated recipient age $(>50$ years versus $\leq 50$ years), recipient race (AA versus others and Hispanic versus others), recipient male gender, recipient BMI $\left(>30 \mathrm{~kg} / \mathrm{m}^{2}\right.$ versus $\leq 25 \mathrm{~kg} / \mathrm{m}^{2}$ ), donor age ( $\geq 60$ years versus $<60$ years), etiology of liver disease (HCV versus others and ALD versus others), and treated ACR episodes as significant risk factors for NODAT in the DDLT cohort. However, subgroup analyses of LDLT recipients demonstrated only ACR (treated ACR versus no ACR) and etiology of liver disease (HCV liver disease versus others and ALD versus others) as significant predictors for NODAT.

Significant risk factors in univariate analyses were included in the multivariate analysis. Table 2 shows unadjusted and adjusted hazard ratios for developing NODAT among all LT recipients. LDLT recipients had a significantly 
TABLE 1: Baseline demographic statistics for DDLT and LDLT recipients.

\begin{tabular}{|c|c|c|c|}
\hline Variables & $\begin{array}{c}\text { DDLT } \\
(n=19582)\end{array}$ & $\begin{array}{c}\text { LDLT } \\
(n=902)\end{array}$ & $P$ value \\
\hline \multicolumn{4}{|l|}{ Recipient age, $n(\%)$} \\
\hline$\leq 50$ & $6652(34)$ & $386(42.8)$ & \multirow[t]{2}{*}{$<0.0001$} \\
\hline$>50$ & $12930(66)$ & $516(57.2)$ & \\
\hline \multicolumn{4}{|l|}{ Recipient gender, $n(\%)$} \\
\hline Female & $6350(32.4)$ & $405(44.9)$ & \multirow[t]{2}{*}{$<0.0001$} \\
\hline Male & $13232(67.6)$ & $497(55.1)$ & \\
\hline \multicolumn{4}{|l|}{ Recipient race, $n(\%)$} \\
\hline Caucasian & $14377(73.4)$ & $761(84.4)$ & \multirow[t]{4}{*}{$<0.0001$} \\
\hline African American & $1784(9.1)$ & $32(3.5)$ & \\
\hline Hispanic & $2320(11.8)$ & $76(8.4)$ & \\
\hline Others & $1101(5.6)$ & $33(3.7)$ & \\
\hline \multicolumn{4}{|l|}{ Recipient BMI, $n(\%)$} \\
\hline$\leq 25$ & $6154(32.9)$ & $396(45.7)$ & \multirow[t]{3}{*}{$<0.0001$} \\
\hline $25-30$ & $6800(36.3)$ & $299(34.5)$ & \\
\hline$>30$ & $5761(30.8)$ & $171(19.7)$ & \\
\hline \multicolumn{4}{|c|}{ Etiology of liver disease, $n(\%)$} \\
\hline ALD & $2481(12.7)$ & $78(8.6)$ & \multirow[t]{5}{*}{$<0.0001$} \\
\hline ALF & $1070(5.5)$ & $24(2.7)$ & \\
\hline $\mathrm{HCV}$ & $9837(50.2)$ & $324(35.9)$ & \\
\hline NASH & $646(3.3)$ & $17(1.9)$ & \\
\hline Others & $5548(28.3)$ & $59(50.9)$ & \\
\hline \multicolumn{4}{|l|}{ MELD score } \\
\hline Mean (SD) & $20.9(9.8)$ & $14.6(5.3)$ & $<0.0001$ \\
\hline \multicolumn{4}{|l|}{ Donor age, $n(\%)$} \\
\hline$<40$ & $8754(44.7)$ & $508(56.4)$ & \multirow[t]{3}{*}{$<0.0001$} \\
\hline $40-60$ & $7926(39.5)$ & $380(42.3)$ & \\
\hline$\geq 61$ & $3102(15.8)$ & $13(1.4)$ & \\
\hline \multicolumn{4}{|l|}{ Donor gender, $n(\%)$} \\
\hline Female & $7876(40.2)$ & $446(49.4)$ & \multirow[t]{2}{*}{$<0.0001$} \\
\hline Male & $11706(59.8)$ & $456(50.6)$ & \\
\hline \multicolumn{4}{|l|}{ Donor race, $n(\%)$} \\
\hline Caucasian & $13304(67.9)$ & $766(84.9)$ & \multirow[t]{4}{*}{$<0.0001$} \\
\hline African American & $3094(15.8)$ & $26(2.9)$ & \\
\hline Hispanic & $2567(13.1)$ & $81(9)$ & \\
\hline Others & $617(3.2)$ & $29(3.2)$ & \\
\hline \multicolumn{4}{|l|}{ Cold ischemia time, $n(\%)$} \\
\hline$<6 \mathrm{~h}$ & $6385(32.6)$ & $658(93.2)$ & \multirow[t]{3}{*}{$<0.0001$} \\
\hline $6-12 \mathrm{~h}$ & 11105 (56.7) & $12(1.7)$ & \\
\hline$>12 \mathrm{~h}$ & $839(4.6)$ & $36(5.1)$ & \\
\hline \multicolumn{4}{|l|}{ Episode of rejection, $n(\%)$} \\
\hline Yes (with treatment) & $967(4.9)$ & $33(3.7)$ & \multirow[t]{4}{*}{0.1267} \\
\hline Yes (no treatment) & $250(1.3)$ & $9(1)$ & \\
\hline No & $17265(88.2)$ & $807(89.4)$ & \\
\hline Missing & $1100(5.6)$ & $53(5.9)$ & \\
\hline
\end{tabular}


TABle 1: Continued.

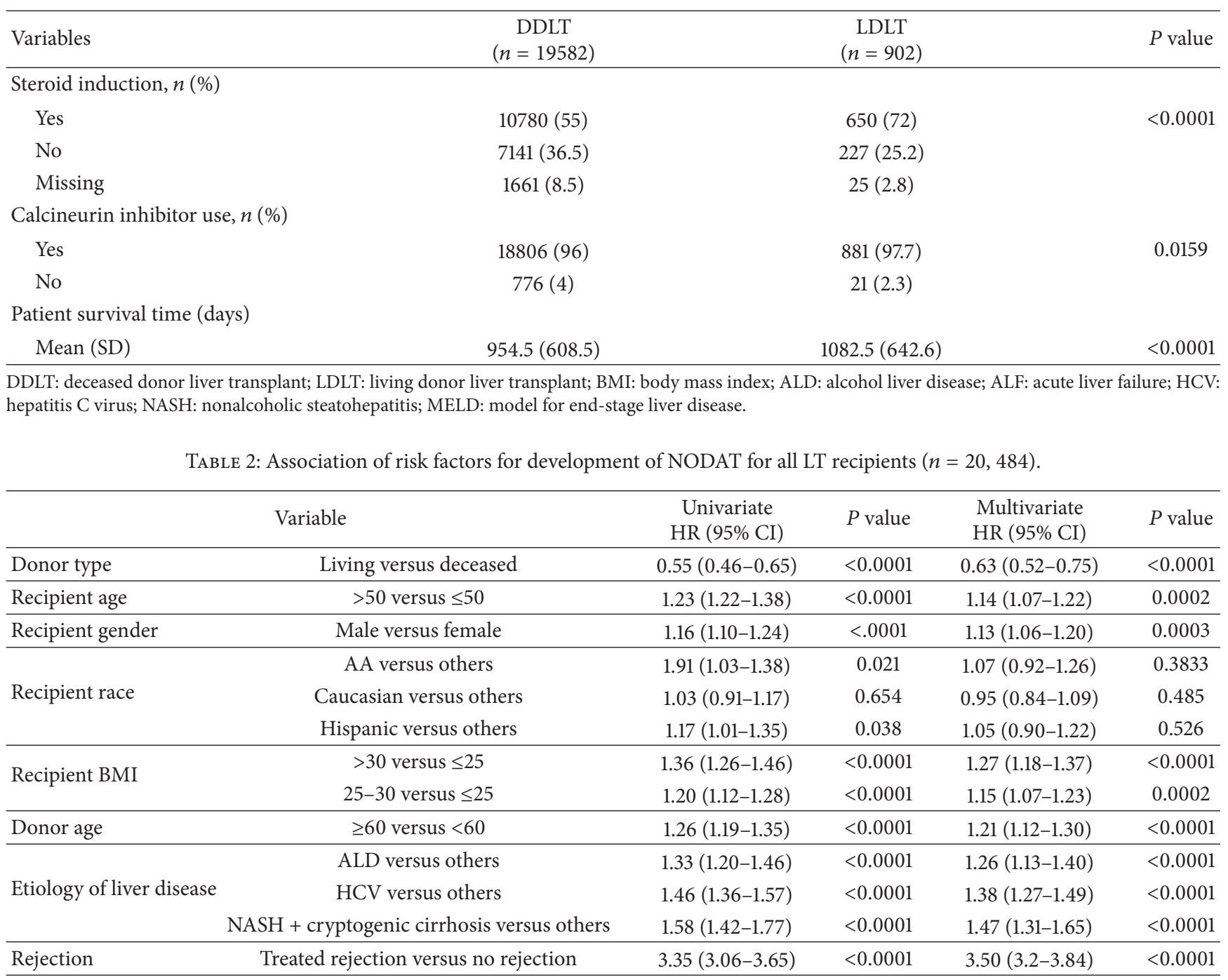

lower risk of NODAT compared to DDLT recipients (LDLT versus DDLT, $\mathrm{HR}=0.63(0.52-0.75) P<0.001)$.

Discrete risk factors for NODAT in LDLT and DDLT recipients were also analyzed separately. The independent risk factors for NODAT in LDLT and DDLT cohorts have been reported in Tables 3 and 4, respectively.

\section{Discussion}

Based on the large multicenter UNOS/OPTN database, the incidence of NODAT at one year after liver transplantation is $7.4 \%$ and $12.5 \%$ among LDLT and DDLT recipients, respectively, with decreasing incidence of NODAT overtime in both cohorts. Our study identified HCV liver disease and treated ACR events as risk factors for development of NODAT in LDLT recipients.

We and others have demonstrated a lower risk of NODAT in LDLT recipients $[1,2]$. In a previous single center study, we reported a decreased risk of NODAT among LDLT recipients (OR $0.22(0.05-0.98) P=0.05)$ [1]. Similarly, Kuo et al.s review of the UNOS/OPTN database also showed lower risk of NODAT in LDLT recipients $(\mathrm{HR}=0.628(0.512-0.769)$ $P<0.001)$ [2]. The decreased risk for NODAT among LDLT recipients could be secondary to favorable donor and recipient characteristics as demonstrated in our study. Recipients receiving LDLT compared to DDLT were younger (50.2 versus 52.7, $P<0.001)$ with lower BMI $\left(26.3 \mathrm{~kg} / \mathrm{m}^{2}\right.$ versus $\left.35.8 \mathrm{~kg} / \mathrm{m}^{2}, P=0.0227\right)$, lower MELD score $(14.6$ versus $20.9, P<0.001)$, and fewer $\mathrm{HCV}$ recipients $(35.6 \%$ versus $50.2 \%, P<0.001)$. Also, donors for LDLT recipients were younger compared to deceased donors ( 37.8 years versus 41.4 years, $P<0.001)$.

We demonstrate $\mathrm{HCV}$ as an important risk factor for NODAT in both LDLT and DDLT recipients. Prior studies have reported conflicting results regarding $\mathrm{HCV}$ as a predictor of NODAT [2-6, 14-16]. Khalili and colleagues demonstrated HCV as an independent predictor of NODAT in a cohort of 555 DDLT recipients (OR 2.6 (1.2-5.7) $P=$ $0.02)$. A meta-analysis study also revealed increased risk of NODAT associated with HCV liver disease (OR 2.46; 
TABLE 3: Independent risk factors for NODAT for all LDLT recipients $(n=902)$.

\begin{tabular}{|c|c|c|c|c|c|}
\hline & Variable & $\begin{array}{c}\text { Univariate } \\
\mathrm{HR}(95 \% \mathrm{CI})\end{array}$ & $P$ value & $\begin{array}{l}\text { Multivariate } \\
\mathrm{HR}(95 \% \mathrm{CI})\end{array}$ & $P$ value \\
\hline Rejection episodes & Treated rejection versus no rejection & $4.12(2.26-7.50)$ & $<0.0001$ & $4.36(2.33-8.15)$ & $<0.0001$ \\
\hline \multirow{3}{*}{ Etiology of liver disease } & ALD versus others & $2.44(1.31-4.55)$ & 0.0049 & $2.45(1.29-4.68)$ & 0.0065 \\
\hline & HCV versus others & $3.67(2.46-5.48)$ & $<0.0001$ & $3.43(2.27-5.17)$ & $<0.0001$ \\
\hline & $\mathrm{NASH}+$ cryptogenic cirrhosis versus others & $1.16(0.45-2.96)$ & 0.759 & $1.23(0.48-3.15)$ & 0.6653 \\
\hline
\end{tabular}

LDLT: living donor liver transplant; ALD: alcohol liver disease; HCV: hepatitis C virus; NASH: nonalcoholic steatohepatitis; HR: hazard ratio; CI: confidence interval.

TABLE 4: Independent risk factors for development of NODAT for all DDLT recipients $(n=19,582)$.

\begin{tabular}{|c|c|c|c|c|c|}
\hline \multicolumn{2}{|r|}{ Variable } & \multirow{2}{*}{$\begin{array}{c}\text { Univariate } \\
\text { HR }(95 \% \text { CI }) \\
1.27(1.20-1.35)\end{array}$} & \multirow{2}{*}{$\begin{array}{l}P \text { value } \\
<0.0001\end{array}$} & \multirow{2}{*}{$\begin{array}{c}\text { Multivariate } \\
\text { HR (95\% CI) } \\
1.14(1.06-1.22)\end{array}$} & \multirow{2}{*}{$\begin{array}{l}P \text { value } \\
0.0003 \\
\end{array}$} \\
\hline Recipient age & $>50$ versus $\leq 50$ & & & & \\
\hline Recipient gender & Male versus female & $1.16(1.10-1.23)$ & $<0.0001$ & $1.13(1.06-1.21)$ & 0.0002 \\
\hline \multirow{3}{*}{ Recipient race } & AA versus others & $1.20(1.03-1.39)$ & 0.0019 & $1.09(0.93-1.28)$ & 0.2994 \\
\hline & Caucasian versus others & $1.05(0.93-1.20)$ & 0.4128 & $0.95(0.83-1.09)$ & 0.4842 \\
\hline & Hispanic versus others & $1.17(1.01-1.35)$ & 0.033 & $1.05(0.90-1.22)$ & 0.540 \\
\hline \multirow{2}{*}{ Recipient BMI } & $>30$ versus $\leq 25$ & $1.32(1.23-1.42)$ & $<0.0001$ & $1.26(1.16-1.35)$ & $<0.0001$ \\
\hline & $25-30$ versus $\leq 25$ & $1.17(1.10-1.26)$ & $<0.0001$ & $1.14(1.06-1.23)$ & 0.0004 \\
\hline Donor age & $\geq 60$ versus $<60$ & $1.26(1.18-1.35)$ & $<0.0001$ & $1.21(1.12-1.30)$ & $<0.0001$ \\
\hline \multirow{3}{*}{ Etiology of liver disease } & ALD versus others & $1.26(1.14-1.39)$ & $<0.0001$ & $1.22(1.10-1.36)$ & 0.0002 \\
\hline & HCV versus others & $1.37(1.28-1.48)$ & $<0.0001$ & $1.34(1.24-1.46)$ & $<0.0001$ \\
\hline & NASH + cryptogenic cirrhosis versus others & $1.53(1.37-1.70)$ & $<0.0001$ & $1.45(1.29-1.63)$ & $<0.0001$ \\
\hline Rejection & Treated rejection versus no rejection & $3.31(3.02-3.62)$ & $<0.0001$ & $3.51(3.20-3.84)$ & $<0.0001$ \\
\hline Donor history of diabetes & Yes versus no & $1.18(1.08-1.30)$ & 0.0002 & $1.20(1.10-1.31)$ & 0.0001 \\
\hline
\end{tabular}

DDLT: deceased donor liver transplant; AA: African American; BMI: body mass index; ALD: alcohol liver disease; HCV: hepatitis C virus; NASH: nonalcoholic steatohepatitis; HR: hazard ratio; CI: confidence interval.

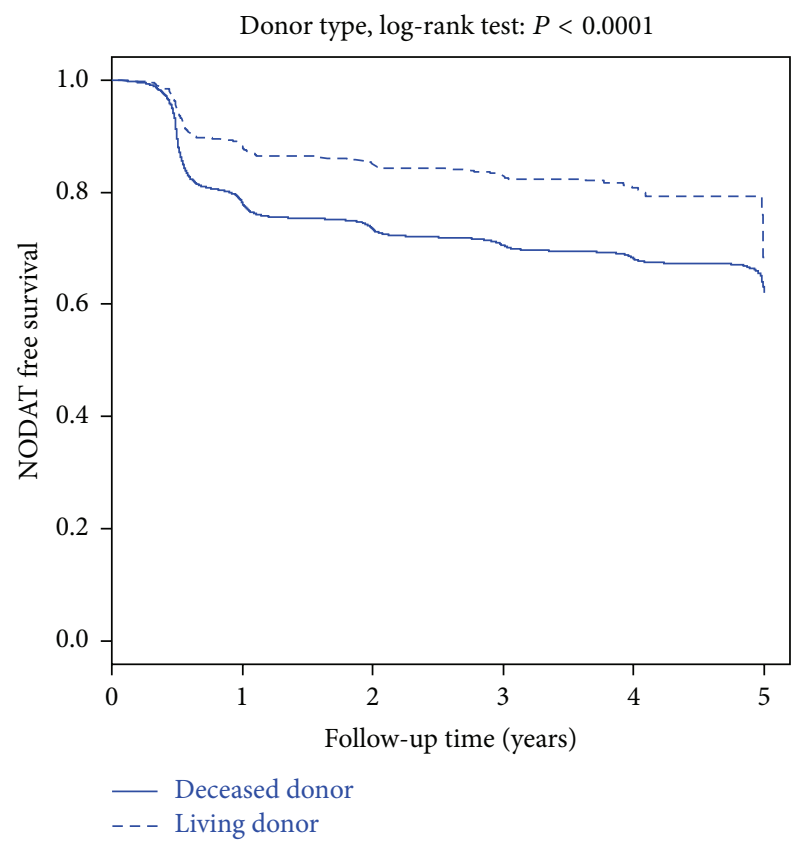

(a)

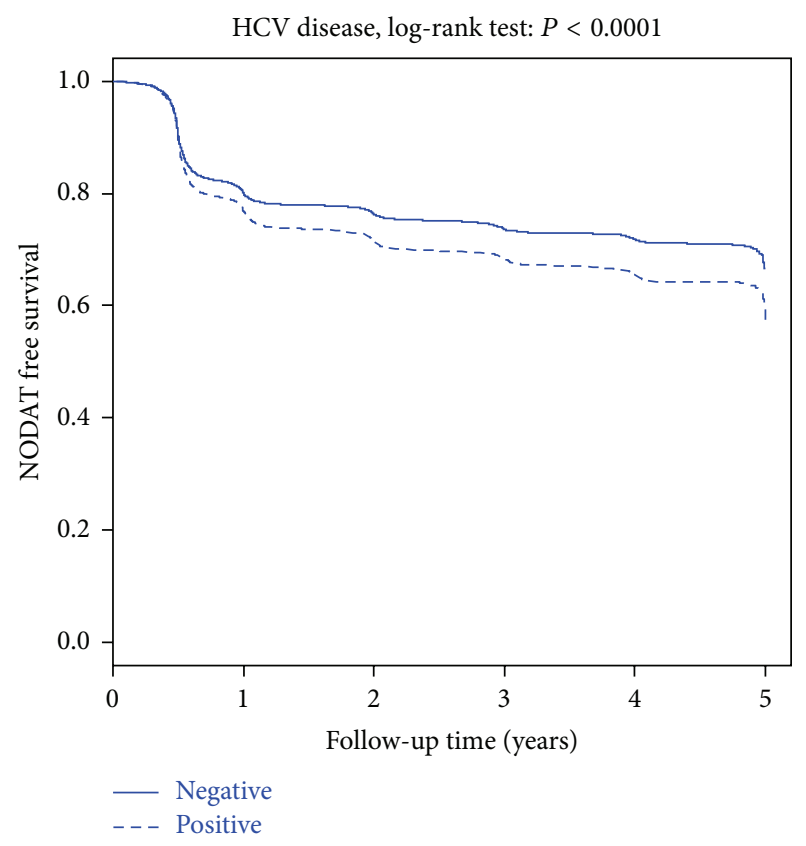

(b)

FIGURE 2: Kaplan-Meier NODAT-free survival curves for LDLT and DDLT recipients according to donor type and HCV. 
95\%CI $(1.44,4.19)$, [16]. However, the association between HCV and NODAT in LDLT recipients has not been well studied. In a Japanese cohort of $62 \mathrm{HCV}$ and 161 non-HCV LDLT recipients, NODAT occurred more frequently in HCV compared to non-HCV patients ( $41 \%$ versus $22 \%, P=0.03$ ). However, HCV did not emerge as a significant predictor for NODAT in multivariate analysis [17]. All HCV patients received preemptive antiviral therapy (interferon $\alpha-2 \mathrm{~b}$ and ribavirin) starting approximately 1 month after LDLT, and 37 out of $62(60 \%)$ recipients were HCV RNA positive at 6 months after transplant. In contrast, our study showed HCV as an independent risk factor for NODAT (HR 1.18 (2.33-8.15) $P<0.001)$.

Our investigation also revealed ACR as a significant predictor for NODAT in both LDLT and DDLT recipients. Few studies have demonstrated increased episodes of ACR in DDLT recipients with NODAT $[9,18]$. In a single center study of DDLT recipients ( $n=138$ ), ACR was seen more commonly in the NODAT group compared to controls with no diabetes (50\% versus $30 \%, P=0.03$ ) [9]. However, treatment regimens used for management of ACR episodes were not reported. In another investigation, Navasa et al. observed significantly higher ACR episodes in 102 DDLT recipients with posttransplant diabetes than in nondiabetic recipients (1.5 versus $1.1, P<0.05)$ at 1 year after transplantation [18]. Our study confirms treated ACR as a predictor for NODAT in both DDLT and LDLT recipients. NODATreducing treatment strategies for ACR should be the focus of future research.

The incidence of NODAT following liver transplantation decreases over time. The long-term incidence of NODAT after liver transplantation in LDLT recipients has not been reported. Navasa and his colleagues also demonstrated a decline in the prevalence of NODAT over time, but the study was limited to a cohort of 88 DDLT recipients followed over a 3-year period [18]. In our study, the decline in the incidence of NODAT may be related to decreased use of maintenance immunosuppression and relatively fewer ACR episodes over time.

Our study has several limitations. First, our analysis may be subjected to reporting error or bias inherent to the large registry database. Second, no standardized diagnostic criteria for identification of NODAT were utilized. Third, there was significant heterogeneity of immunosuppression protocols and antiviral regimens after transplantation across different centers. Fourth, the MELD score reported includes exception points and could be a confounding factor. Lastly, traditional risk factors such as recipient family history of diabetes and pretransplant impaired fasting glucose were not available for analysis.

In summary, the incidence of NODAT at 1 year after liver transplantation for LDLT and DDLT recipients was 7.4\% and $12.5 \%$, respectively. LDLT recipients had a lower incidence, fewer risk factors, and higher 5-year NODAT-free survival compared to DDLT recipients. Due to the higher incidence of NODAT in the first six months following liver transplantation, early intervention during this time period may prevent the development of NODAT. Large prospective studies are needed to identify the impact of NODAT on patient and graft outcomes in both LDLT and DDLT recipients.

\section{Abbreviations}

UNOS/OPTN: Organ Procurement and Transplant Network/United Network For Organ Sharing

NODAT: $\quad$ New onset diabetes mellitus after

$\begin{array}{ll} & \text { transplantation } \\ \text { LDLT: } & \text { Living donor liver transplant }\end{array}$

DDLT: $\quad$ Deceased donor liver transplant

LT: $\quad$ Liver transplantation

HCV: $\quad$ Hepatitis C virus

ACR: $\quad$ Acute cellular rejection

BMI: $\quad$ Body mass index

MELD: $\quad$ Model for end-stage liver disease

NASH: $\quad$ Nonalcoholic steatohepatitis

ALD: $\quad$ Alcohol liver disease

ALF: $\quad$ Acute liver failure

HR: Hazard ratio.

\section{Conflict of Interests}

The authors declare that there is no conflict of interests.

\section{References}

[1] E. J. Carey, B. A. Aqel, T. J. Byrne et al., "Pretransplant fasting glucose predicts new-onset diabetes after liver transplantation," Journal of Transplantation, vol. 2012, Article ID 614781, 6 pages, 2012.

[2] H.-T. Kuo, M. S. Sampaio, X. Ye, P. Reddy, P. Martin, and S. Bunnapradist, "Risk factors for new-onset diabetes mellitus in adult liver transplant recipients, an analysis of the organ procurement and transplant network/united network for organ sharing database," Transplantation, vol. 89, no. 9, pp. 1134-1140, 2010.

[3] F. Saliba, M. Lakehal, G.-P. Pageaux et al., "Risk factors for new-onset diabetes mellitus following liver transplantation and impact of hepatitis $\mathrm{C}$ infection: an observational multicenter study," Liver Transplantation, vol. 13, no. 1, pp. 136-144, 2007.

[4] S. G. Tueche, "Diabetes mellitus after liver transplant new etiologic clues and cornerstones for understanding," Transplantation Proceedings, vol. 35, no. 4, pp. 1466-1468, 2003.

[5] S. Saab, A. Shpaner, Y. Zhao et al., "Prevalence and risk factors for diabetes mellitus in moderate term survivors of liver transplantation," American Journal of Transplantation, vol. 6, no. 8, pp. 1890-1895, 2006.

[6] L. Oufroukhi, N. Kamar, F. Muscari et al., "Predictive factors for posttransplant diabetes mellitus within one-year of liver transplantation," Transplantation, vol. 85, no. 10, pp. 1436-1442, 2008.

[7] J. I. Moon, R. Barbeito, R. N. Faradji, J. J. Gaynor, and A. G. Tzakis, "Negative impact of new-onset diabetes mellitus on patient and graft survival after liver transplantation: long-term follow up," Transplantation, vol. 82, no. 12, pp. 1625-1628, 2006.

[8] X. Xu, Q. Ling, Z.-L. He, F. Gao, and S.-S. Zheng, "Posttransplant diabetes mellitus in liver transplantation: hangzhou experience," Hepatobiliary and Pancreatic Diseases International, vol. 7, no. 5, pp. 465-470, 2008. 
[9] P. R. John and P. J. Thuluvath, "Outcome of patients with newonset diabetes mellitus after liver transplantation compared with those without diabetes mellitus," Liver Transplantation, vol. 8, no. 8, pp. 708-713, 2002.

[10] S. Baid, A. B. Cosimi, M. Lin Farrell et al., "Posttransplant diabetes mellitus in liver transplant recipients: risk factors, temporal, relationship with hepatitis $\mathrm{C}$ virus allograft hepatitis, and impact on mortality," Transplantation, vol. 72, no. 6, pp. 1066-1072, 2001.

[11] P. Marchetti, "New-onset diabetes after liver transplantation: from pathogenesis to management," Liver Transplantation, vol. 11, no. 6, pp. 612-620, 2005.

[12] P. T. Pham, P. M. Pham, S. V. Pham, P. A. Pham, and P. C. Pham, "New onset diabetes after transplantation (NODAT): an overview," Journal of Diabetes, Metabolic Syndrome and Obesity, vol. 4, pp. 175-186, 2011.

[13] J. Zhao, L. Yan, B. Li et al., "Diabetes mellitus after living donor liver transplantation: data from mainland China," Transplantation Proceedings, vol. 41, no. 5, pp. 1756-1760, 2009.

[14] M. Khalili, J. W. Lim, N. Bass, N. L. Ascher, J. P. Roberts, and N. A. Terrault, "New onset diabetes mellitus after liver transplantation: the critical role of hepatitis C infection," Liver Transplantation, vol. 10, no. 3, pp. 349-355, 2004.

[15] S. Mirabella, A. Brunati, A. Ricchiuti, A. Pierini, A. Franchello, and M. Salizzoni, "New-onset diabetes after liver transplantation," Transplantation Proceedings, vol. 37, no. 6, pp. 2636-2637, 2005.

[16] T. Chen, H. Jia, J. Li, X. Chen, H. Zhou, and H. Tian, "New onset diabetes mellitus after liver transplantation and hepatitis C virus infection: meta-analysis of clinical studies," Transplant International, vol. 22, no. 4, pp. 408-415, 2009.

[17] Y. Kishi, Y. Sugawara, S. Tamura, J. Kaneko, Y. Matsui, and M. Makuuchi, "New-onset diabetes mellitus after living donor liver transplantation: possible association with hepatitis C," Transplantation Proceedings, vol. 38, no. 9, pp. 2989-2992, 2006.

[18] M. Navasa, J. Bustamante, C. Marroni et al., "Diabetes mellitus after liver transplantation: prevalence and predictive factors," Journal of Hepatology, vol. 25, no. 1, pp. 64-71, 1996. 


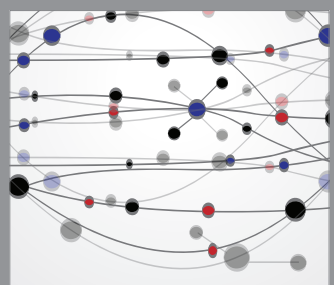

The Scientific World Journal
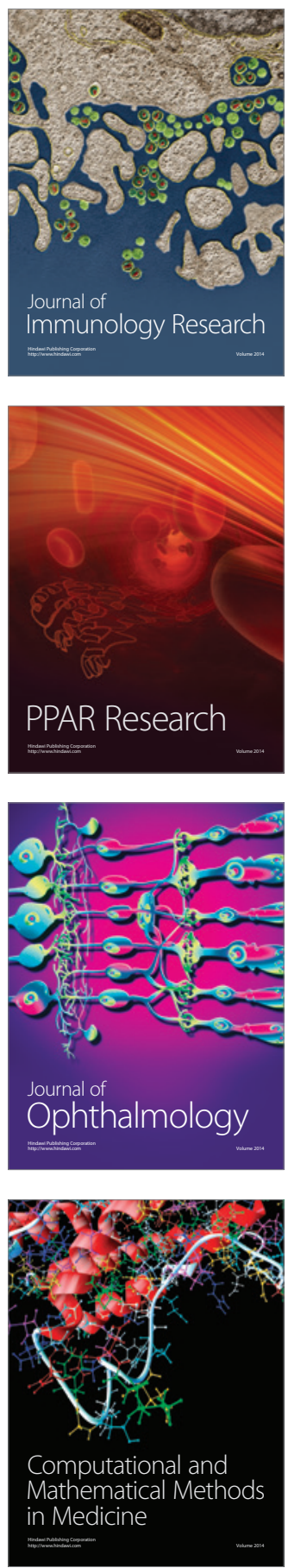

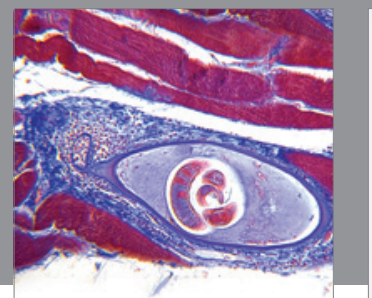

Gastroenterology

Research and Practice
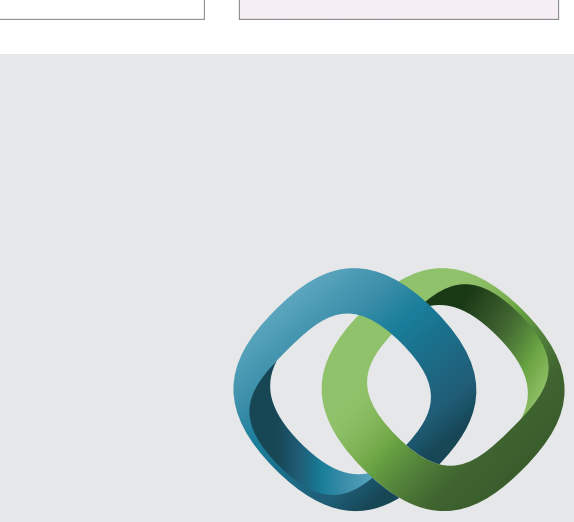

\section{Hindawi}

Submit your manuscripts at

http://www.hindawi.com
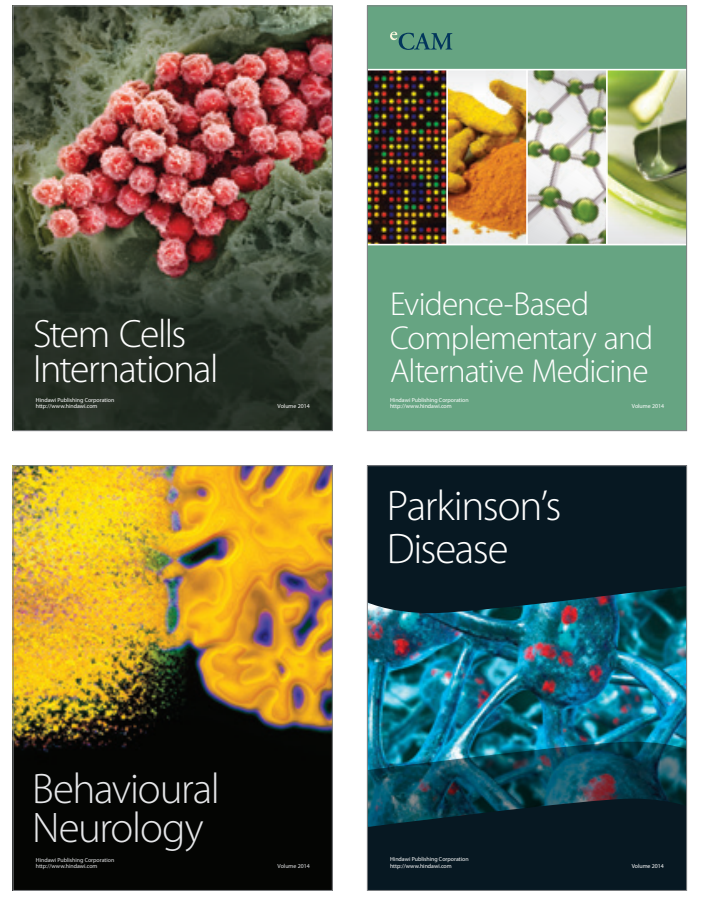
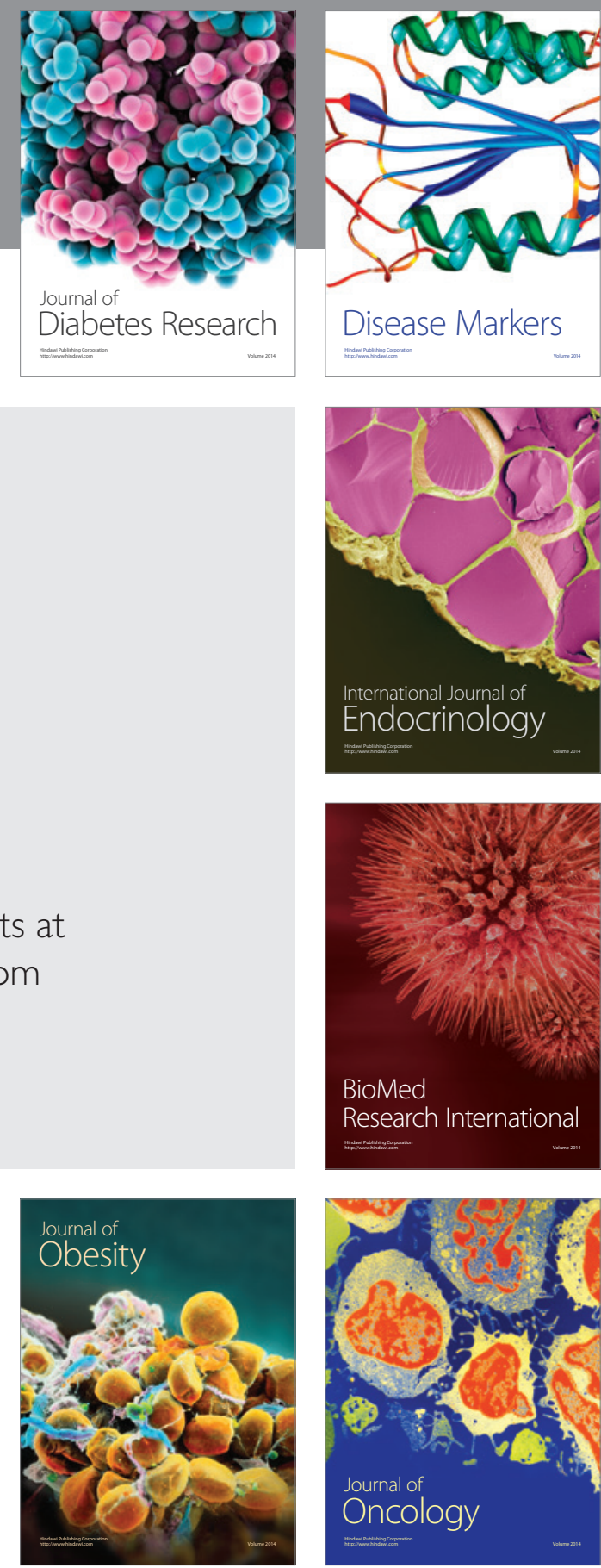

Disease Markers
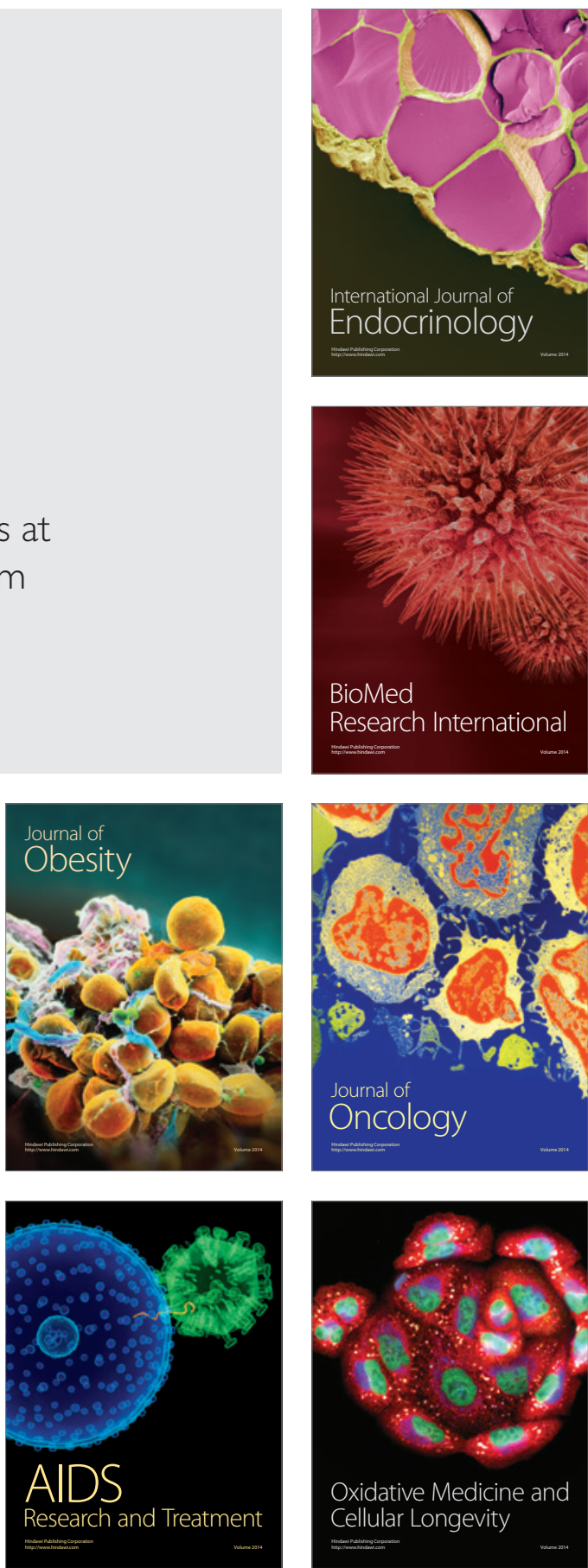